\title{
NECESITAMOS CAMBIO
}

\author{
CHANGE WE NEED
}

\section{LUIS BORTESI LONGHI ${ }^{1}$}

Docente Asociado de la Facultad de Ciencias Contables, UNMSM

[Recepción: Abril de 2009 / Conformidad: Mayo de 2009]

\section{RESUMEN}

El presidente de los Estados Unidos Barack Obama focalizó su campaña electoral con un simple, claro y certero mensaje: CAMBIO. Al comienzo la fórmula consistió en repetir ¡Change, we can believe in it! , luego abrevió el disparo con la frase que figura en el título del presente artículo y en las postrimerías de la contienda solamente repetía como un dardo una única palabra “¡Change! “, ¡Cambio! Desde un punto de vista objetivo y lógico, es decir teórico, no se podría haber admitido a priori que la nación que se reputa la más poderosa y rica del planeta pudiese ser vulnerable a la idea del cambio porque se presume que después de todo los Estados Unidos habrían sido una especie de modelo y paradigma de lo que se llama la "Sociedad Desarrollada" y en consecuencia el sentido común dictaría más bien todo lo contrario, como ser reafirmar las instituciones y confirmar las reglas de juego y el sentido de la vida, dado que el sueño americano tendría que tener el significado de la máxima calidad de vida, pero evidentemente la experiencia electoral demostró que el pueblo se encuentra insatisfecho y que el olfato político del candidato Obama acertó en el blanco removiendo el corazón y las conciencias del pueblo americano. En el presente artículo el propósito principal consiste en analizar las causas y circunstancias de este fenómeno psicológico, social y político.

Palabras clave: Decepción/Angustia/Cambio/ Esperanza

1 Doctor en Economía. E- mail: luisbortesil@hotmail.com

\begin{abstract}
During his campaign president Obama focalized his message pointing skillful the change as the center of his speech. At the start the message consisted in repeating ichange, we can believe in it! , and then "change we need" for, finally, like a dart, employing only one word: change. From a theoretical and logical point of view is not easy to assimilate a priori that fact where the most powerful nation in the whole world could be vulnerable because the idea of change, on the contrary, it is supposed that, after all, the USA people means a model to follow as a paradigm of "Developed Society" and therefore a path to pursue, confirming and reinforcing their institutions, the rules, the raison of life, the american dream. Many people still believe in the highest quality of life in America among the entire world. But the electoral experience showed the things in another way demonstrating that the american people is dissatisfied and that the political sense of smell of the candidate Obama target straight in the bull removing the heart and the consciences of the nation. The main purpose in this article is to analyze the causes and circumstances around this phenomenon from a point of view psychological, social and politic.
\end{abstract}

Key words: Disappointment, Stress, Change, Hope. 


\section{INTRODUCCIÓN}

Ya el famoso pensador alemán Oswald Spengler advertía en su libro "La Decadencia de Occidente" (1918) que resulta inexorable la aplicación de los ciclos a todo imperio que alcanza el apogeo para luego declinar. El eximio filósofo de la historia, el británico Arnold Toynbee contemporáneo de Spengler, encabezó una escuela contraria argumentando y tratando de demostrar que en realidad no está necesariamente decretada la decadencia después del apogeo, sino que más bien todo depende de la capacidad de respuesta de los pueblos frente a las circunstancias de sus desafíos, y que incluso los retos son capaces de estimular una reacción positiva de prosperidad. Pero Toynbee no pudo demostrar ningún caso histórico que reforzara su aserto. La historia documentada y objetiva enseña que esta constatación universal con respecto a la inexorable decadencia no tiene excepciones porque la religión egipcia, el Imperio Romano, Napoleón, Hitler, todos, desarrollaron un trayecto que comprueba la inevitable decadencia. La cuestión que no está resuelta es la de la duración del arco de tiempo que describe cada ciclo entre su nacimiento, su punto de inflexión y su declive. El gráfico del ciclo de Adolfo Hitler, por ejemplo, es de duración cortísima pese a que se había anunciado la era mesiánica del nacional socialismo para perdurar mil años.

Otra observación alusiva a este tema es que en realidad el desarrollo del ciclo en su fase descendente no acusa una línea recta sino que se verifican una serie de "reciclos" que permiten una recuperación temporal aunque la trayectoria de máxima tenga siempre una pendiente hacia abajo hasta que se llegue a una especie de estertor final y, si se mira bien, la misma experiencia se tiene frecuentemente con los pacientes si nos referimos a la salud humana y su resquebrajamiento en la senectud previa al deceso

Los Estados Unidos demuestran una historia pujante como joven colonia inglesa y es a partir de las dos guerras mundiales, especialmente la segunda, que cobran la hegemonía universal y trasladan a su merced a todas las instituciones bajo su dominio. Las Naciones Unidas, que había sido establecida en Ginebra luego de la Primera Guerra Mundial como Societè Des Nations, es literalmente transplantada a Nueva York. Se ordena la política monetaria creando el Banco Central de los bancos centrales de todo el planeta via el Fondo Monetario Internacional. El GATT habrá de regular el comercio internacional, el Banco Mundial también ocupa un lugar central y se consolida la prioridad del dólar al comienzo con el sistema del Gold Standard que más tarde se desprenderá de su relación con el oro (a razón de treinta y cinco dólares por onza troy) para quedar llana y simplemente en el sistema Dollar Standard que tiene un soporte exclusivamente fiduciario, es decir su valor depende tan sólo de la credibilidad y la fe.

Otro movimiento importante y definitivo es ejecutado en el campo político militar con la creación de la NATO, que es el tratado organizado del Atlántico Norte con el objeto de neutralizar a la entonces muy poderosa URSS que le marcaba a Estados Unidos una complementariedad de poder, lo que se llama la bipolaridad. Un escándalo que permanece sin ser purgado en la historia reciente de la humanidad es el caso de las Naciones Unidas que pese a albergar a los 200 países del mundo no tienen carácter democrático puesto que el verdadero gobierno de la ONU recae sobre los cinco grandes vencedores de la Segunda Guerra Mundial y entre los cinco hay un predominio hegemónico, hasta ahora, de los Estados Unidos de Norteamérica. 


\section{GLORIA Y DECADENCIA}

Dentro de los cinco grandes conquistadores al cabo de la Segunda Guerra Mundial habían dos tendencias opuestas: Estados Unidos, el Reino Unido y Francia estaban orientados por la inspiración capitalista, mientras que la Unión Soviética y la China por la comunista. Conformaron el Consejo de Seguridad pero en su seno comenzó a "hervir", paradójicamente, la llamada "guerra fría". El espacio geopolítico donde se midió la rivalidad fue en la antigua Indochina con el desencadenamiento de la infausta guerra de Vietnam que tuvo lugar durante casi veinte años (1958-1975) en la península. China y Unión Soviética apoyaron al Viet Cong con su centro en Hanoi y los Estados Unidos acompañado de algunos socios menores respaldaron al sur, república de Vietnam sede central en Saigón. Si se tuviese indagar cuándo comienza la declinación del imperio norteamericano indudablemente la respuesta se encuentra en la guerra de Vietnam que galvaniza el desastre de la prepotencia pura desplazando 50,000 soldados de élite entrenados para aplicar métodos brutales y miles de aviones, helicópteros, bombas y armas químicas frente a la pura motivación moral, al coraje y a la convicción. EE.UU. demostró su total falta de escrúpulos utilizando armas químicas, el llamado "agente naranja" que es un herbicida en polvo expulsado masivamente a presión desde aviones de combate y helicópteros artillados para envenenar a la población a la vez que desforestar los campos. Es bien sabido, sin embargo, que esta alevosa práctica le costó mucho al propio pueblo americano por los daños infligidos a sus propios soldados y los reclamos posteriores de indemnización. Frente a la tecnología los vietnamitas emplearon la táctica de guerra de guerrillas, con sorpresa, y trampas artesanales como las famosas "estacas punji" que con- tenían estiércol en la punta para producir la gangrena.

Lo cierto es que Estados Unidos se retira con humillación en el año 1973 dejando como saldo la muerte de cinco millones de personas la mayoría civiles y daños ambientales incalculables, pero el saldo doloroso le rebota al pueblo americano y se configura en el llamado "síndrome de Vietnam" depresión aguda, desmoralización, vergüenza, todo lo cual conduce a un fenómeno histórico y extraordinariamente significativo que es el del movimiento hippie donde los jóvenes declarados en rebeldía pacífica le dan la contra al sistema enarbolando el lema "haz el amor y no la guerra” y se dedican a ejercicios místicos y al yoga, fuman mariguana, se visten con plumas y con harapos y calzan sandalias.

Hay que comprender que la trayectoria decadente del ciclo no corresponde a una línea recta vertical sino, como ya se ha dicho, a un conjunto de espirales cuya tendencia general es hacia abajo. Pero, sin ninguna duda, el imperio americano marca el comienzo de su decadencia con la acre experiencia vivida en la antigua Indochina.

Pero obviamente no renuncian a su poder sino que tercamente lo afianzan y pretenden renovarlo no importa cual audacia sea necesario perpetrar. Muchos son los ejemplos que pueden ilustrar dicha conducta, la abortada organización para invadir Cuba, el suministro de armas a los contra en Nicaragua, son algunos.

Cuando por la noche del jueves 9 de noviembre de 1989 cayó por tierra el famoso muro de Berlín simbolizando a su vez la fragmentación de la Unión Soviética, el fin de la Guerra Fría y en resumen la aparente entronización definitiva e irreversible del capitalismo coronando como a Napoleón en Notre Dame a Estados Unidos, naturalmente éstos se envalentonaron sin remedio. 
Dando una prueba más de absoluta arbitrariedad, el 20 de diciembre de 1989 el gobierno del entonces presidente George Herbert Walker Bush montó la operación llamada "operation just cause" y dispuso la invasión militar contra Panamá para capturar físicamente al general Manuel Antonio Noriega jefe del comando conjunto y vigente dictador en el istmo. La marina de guerra desplegó 26,000 efectivos y la 82a división aerotransportada 12,000. El presidente Bush que había sido jefe de la CIA había declarado......"nuestra responsabilidad es la de dirigir al mundo" y en esta ocasión argumentó que la incursión armada tenía como propósito proteger la vida de ciudadanos de USA, defender los derechos humanos en Panamá y detener a Noriega por delito de narcotráfico.

El resultado de la operación "causa justa" fue el bombardeo de muchos barrios y cuarteles, particularmente la zona de El Chorrillo donde se encontraban partidarios y el propio cuartel del general Noriega, con un saldo de 4500 muertos e incalculables pérdidas económicas. Se decidió reconocer en la presidencia de Panamá a Guillermo Endara al cual se le tomó juramento y a Noriega se lo llevaron preso a una cárcel de Estados Unidos donde purga condena por 40 años.

Lo interesante de este episodio es el hecho que, algún tiempo después, John Dimitri Negroponte, diplomático norteamericano y también miembro de la CIA confesó que el objetivo real de la invasión a Panamá era mantener el control del canal debido a que el gobierno de Noriega entrañaba un peligro de nacionalización.

\section{LA INVASIÓN DE IRAQ}

El último episodio político y bélico que desacredita severamente a Estados Unidos y merece rechazo prácticamente universal es el de la invasión contra el gobierno de Saddam Hussein cuya responsabilidad recae directamente sobre el más controvertido personaje que jamás haya gobernado nación alguna: el presidente George Walker Bush.

Lo primero que resulta espantoso y desde un punto de vista civilizado, inconcebible, es que Bush haya proclamado abierta e impúdicamente su teoría de la "guerra preventiva" según la cual a los Amos del Mundo les asiste el derecho de atacar a mansalva cualquier territorio o nación si es que sospechan, aún sin contar con ninguna prueba, que dicho territorio o nación podría representar un peligro para USA. Bush declaró que el gobierno de Saddam Hussein poseía armas de destrucción masiva tales como armas químicas, biológicas y nucleares y que además presumía que estaba en secretos contactos con Al Qaeda y juzgó dicha circunstancia como "el eje del Mal". Quien no quedó atónito quedó estupefacto, porque a partir de tal aserto propuso en el seno de las Naciones Unidas una invasión armada contra Iraq. Tres miembros del Consejo de Seguridad se opusieron abiertamente. Francia, China y Rusia declararon su disconformidad, además de países tales como Alemania, México y Chile. El gobierno Británico encabezado por Tony Blair secundó la propuesta pero el Secretario General Kofi Annan, cumpliendo su deber e interpretando el sentir de la comunidad internacional, prohíbe la invasión y declara que sería ilegal.

Sin embargo, dando prueba de la pura prepotencia, el 20 de marzo del año 2003 la coalición formada por Estados Unidos y Gran Bretaña dispone la invasión y despliega un enorme contingente militar. Estados Unidos provee 225,000 soldados, 1600 tanques Abrams M1 y Bradleys M2, 400 helicópteros, 350 bombarderos y cuatro portaviones: el Constellation, el H. Truman, el Lincoln y 
el Rooselvet. La Gran Bretaña emplea 45,000 soldados, 270 blindados, 100 bombarderos, 16 buques de guerra y un portaaviones.

Se captura la ciudad de Baghdad y las tropas se esparcen por el territorio iraquí aunque, por espacio de años y hasta nuestros días se producen atentados permanentes que arrojan dantescos saldos en vidas humanas, casi siempre de civiles, incendios y "destrucción masiva”. Ha llegado un momento en que los avisos que publica diariamente la prensa consignando 40, 80 o 100 muertos no llaman mayormente la atención sino que aparecen en una página secundaria del diario en un pequeño recuadro: "atentado en Iraq....... cincuenta muertos".

Saddam Hussein fue ejecutado en la horca en diciembre del 2006. Más de 30,000 personas inocentes, niños, mujeres, ancianos, todos civiles, perdieron la vida en la invasión de Iraq. Saddam no poseía armas de destrucción masiva ni estaba tampoco en secretos contactos con Al Qaeda. El ejército iraquí no pudo utilizar su obsoleta fuerza aérea ya que ningún avión pudo decolar para combatir a la fuerza aérea invasora. El gobierno de Hussein sufría un embargo desde el año 1991 a raíz de su intento de anexarse Kuwait y en consecuencia su material bélico totalmente de origen soviético era inservible. Contó tan sólo con misiles de interceptación Patriot y al final dispuso de la guardia republicana de palacio que fue incapaz de detener el ingreso enemigo y la ocupación de Bagdad y tuvo que dispersarse entre la población civil para incorporarse a la guerra de guerrillas que, como demuestra la historia, suele ser inextinguible.

Al igual que en el caso de la invasión contra Panamá, lo sarcástico y penoso del asunto resulta ser la verdadera motivación para agredir a Iraq. En sus memorias publicadas el año 2007 Alan Greenspan, alto funcionario ame- ricano y expresidente de la Reserva Federal, aseguró que el interés real de la operación fue el de controlar las gigantescas reservas petroleras que ese país árabe posee puesto que es uno de los principales productores mundiales. Greenspan no hace sino confirmar lo que cualquier persona medianamente sensata ya suponía.

\section{LA CRISIS FINANCIERA INTERNACIONAL}

Desde el año 1929 no se experimenta algo tan peligroso, grave y doloroso, como lo que el planeta está viviendo ahora con el descalabro financiero originado, nuevamente, en los centros neurálgicos estadounidenses. La crisis del 29 fue producto de una aceleración de sobreproducción que desembocó en el peor fenómeno monetario que existe que es la deflación, la disminución de precios. Luego de su triunfo al cabo de la Primera Guerra Mundial todo se aceleró en los Estados Unidos de Norteamérica, hasta la música con el charlestón, la velocidad de los vehículos la precocidad sexual, y la actividad fabril y financiera. Eso determinó una saturación de los mercados, la deflación y su consecuencia que es la puesta a pérdida de las empresas que se ven obligadas primero, a reducir personal y luego a tener que cerrar, arrastrando con esto a todos los bancos cuyos acreedores en deuda y en déficit generan la ruina holística, es decir total.

Ahora, 78 años después, en los Estados Unidos se origina otro epicentro catastrófico pero con la diferencia de que el mundo contemporáneo se encuentra globalizado lo que quiere decir que sufre una solidificación donde cualquier vibración repercute con intensidad en todo el resto, porque el fenómeno de la globalización determina que los espacios y 
los tiempos sea mucho más cortos como si la tierra se hubiera achicado en proporciones, se hubiera reducido de tamaño. Todo está mucho más interconectado e interdependiente de donde todos los riesgos son sistémicos, los efectos retroalimentan las causas vertiginosamente y es muy difícil atajar algún problema de raíz.

El crack de 1929 duró en su etapa más severa hasta 1932 y se reflejó concretamente en el descalabro de la Bolsa de Valores en Wall Street en Nueva York. Tuvo también repercusiones internacionales como que, por ejemplo, motivó la caída del presidente peruano Augusto Bernardino Leguía Salcedo que había contraído numerosas obligaciones financieras en el extranjero para sufragar obras públicas. El comandante Luis Sánchez Cerro encabezó un golpe de estado sustentado precisamente en esa debacle.

Pero comparar lo acontecido entonces con lo que ocurre en nuestros días no procede porque sería algo así como evaluar los daños que produce un terremoto en una vivienda de dos pisos y de madera, con los estragos del mismo terremoto en un edificio de veinte pisos construido con concreto armado.

Cuando se discute la causa de la crisis financiera originada en los Estados Unidos seguramente a partir de los años 2004, 2005 y brotada su virulencia manifestándose explícitamente en la segunda mitad del año 2007, la explicación difiere. Algunos, bien intencionados aunque a veces ingenuos, analistas quieren ver el origen en fallas técnicas de tipo humano. Dicen que no se calculó bien el equilibrio entre apalancamiento bancario y préstamos, y tampoco se calculó bien el desenvolvimiento del mercado del Real State o sea del mercado inmobiliario.

Sin embargo está demostrado sin atenuante alguno que el origen verdadero de la crisis es la inmoralidad y la codicia.
En los Estados Unidos es costumbre generalizada adquirir bienes domésticos a plazos vía el procedimiento de la hipoteca (mortgage) y toda la clase media compra automóviles, electrodomésticos, que renueva muy frecuentemente, cada dos o tres años. Pero también la vivienda la adquieren con créditos hipotecarios.

Durante el último quinquenio el mercado hipotecario acusó una notable tendencia de incremento lo que impulsó naturalmente al sector construcción y en vista de ese auge numerosas brigadas de jóvenes animados por las fabulosas comisiones por concepto de venta colocaron desmesurados contratos sin importarles mayormente la verdadera capacidad de endeudamiento del comprador. Se ha comprobado que el principal argumento para convencer a un comprador dubitativo, cuyo sueldo evidentemente no justificaba contraer una obligación de tamaño de la hipoteca, fue explicar que la casa prácticamente se pagaría sola porque sus valores estaban en continuo aumento. Así, por ejemplo, a una persona modesta que ganase 3000 dólares mensuales y tuviese que disponer de 2800 para amortizar la hipoteca de una casa de 300,000 dólares, se le diría que dicho inmueble al cabo de un par de años valdría 500,000 y por lo tanto el asunto prácticamente se arreglaría sólo.

Fue de esa manera perversa que proliferaron los préstamos tristemente célebres "sub prime" que literalmente significa "de segunda categoría" con papeles que sumados en todo el país alcanzaron cifras astronómicas. La codicia entonces se multiplicó porque las instituciones financieras que poseían esos activos por deuda, los empaquetaron y dieron origen a "derivados" que se dieron en llamados "instrumentos financieros estructurados" para venderlos a otras instituciones financieras. $Y$ resultó que, a su vez, estas otras instituciones 
financieras revendieron los papeles generando una cadena de verdadero "desvalor". El presidente Bush incorporó al final de su mandato un nuevo término, un neologismo que previamente no figuraba en el diccionario de los economistas que es el de "activos tóxicos" porque en el paquete estaban incluidas deudas "malas" que contaminan a las "buenas". (Ya anteriormente había estrenado otro neologismo: "la guerra preventiva")

Cuando esa espiral tocó su punto de inflexión y comenzaron las víctimas de la ilusión a dejar de pagar la consecuencia fue desastrosa, porque el sector construcción colapsó, se dejaron de comprar las casas en oferta y se dejaron de pagar las deudas contraídas. Los bancos y las demás instituciones financieras que habían entrado al juego, incluso una poderosa aseguradora, se desplomaron como un castillo de naipes.

Ahora bien, ¿quiénes son los responsables de tamaña estafa disfrazada? En primer lugar los contadores (accountant) que se dieron maña para presentar estados financieros sin ajustes ni provisiones de riesgo. Pero obviamente las autoridades oficiales, los organismos reguladores, no cumplieron su deber $y$ las famosas empresas clasificadoras de riesgo mintieron. Si se tiene que señalar específicamente la responsabilidad, seguramente esta recae sobre la función de los auditores.

Por separado y enfocando las cosas de manera más profunda, filosófica e integral, lo que es necesario criticar y evaluar, es decir aquello que necesita un CAMBIO radical es la persecución a muerte de los paraísos fiscales y la prepotencia de la economía virtual sobre la economía real.

Un dato injusto y repugnante resulta en el hecho de que pese a la magnitud de la catástrofe financiera que compromete a todo el mundo, nadie ha sido señalado como responsable mientras que se sabe que los paraísos fiscales han engrosado sus arcas fruto de esas especulaciones con dinero mal habido. Es cierto que a raíz de la crisis financiera internacional afloraron algunas pirámides puesto que los flujos de depósitos se interrumpieron y en esos específicos casos si se ha condenado a algunos individuos. Pero la gigantesca cadena delictiva central permanece impune.

De un tiempo a esta parte las finanzas envuelven y subordinan al circuito económico verdadero, para decirlo en otras palabras, la especulación y el espíritu lúdico ocupan una jerarquía superior a la actividad del trabajo y sus frutos que son la producción de bienes y servicios. Se privilegia la timba frente a la actividad visible y honrada. La economía real se sitúa en el pasado y en el presente y la consecuente cosecha de sus frutos producto del trabajo. La economía llamada "virtual" en cambio representa siempre una abstracción pura y los elementos que se conjugan en ella son el futuro, el interés dinerario y el riesgo pero, repetimos, siempre su escenario está proyectado al futuro. La sofisticación y la abstracción de los instrumentos financieros, que no son más que papeles, llega a tal límite que al final de cuentas se pierde el rastro de su origen y terminan por carecer de cualquier valor real. El llamado "juego bursátil" es un buen ejemplo de las posibilidades de prepotencia de la economía virtual.

\section{OBAMA Y EL CAMBIO}

Como se desprende de todo lo anteriormente descrito no es poco lo que el presidente Barack Obama tiene que cambiar. Un hecho particularmente curioso, como si se tratara de una broma agria del destino es que el presidente también se llama Hussein y tiene vínculos históricos y de afinidad con el Is- 
lam. (Desde un punto de vista supersticioso también se puede ver sintonía entre Obama y Osama). La verdad es que nadie hubiera anticipado que en los Estados Unidos se produjese una experiencia electoral con las características y resultados de esta última en la que salió electo este joven tan pujante y tan bien intencionado que ahora sin ninguna exageración constituye una esperanza providencial.

Pero no le resulta fácil la tarea, de ninguna manera y es más, en la misma medida en que están concentradas las esperanzas, puede sobrevenir una decepción que podría ser catastrófica.

Obama tiene que nadar contra la corriente y desmentir la ley de los ciclos demostrando que los Estados Unidos de América siguen siendo los que controlan al mundo cuando en realidad precisamente todo el mundo les ha perdido el respeto por su falta de moral. Es oportuno recordar que los conceptos de autoridad y poder no constituyen sinónimo porque el poder deriva de la fuerza y la violencia y por lo tanto el poder se impone, mientras que la autoridad o el verdadero liderazgo es consecuencia de la sabiduría, del ejemplo que atrae de por sí y que es digno de imitación. Estados Unidos tiene poder, todavía, porque posee la organización bélica más fuerte y mortífera del mundo, pero autoridad, que es un hecho moral, no le queda ni una pizca.

Tiene sobre las espaldas la deuda pública más alta del mundo, un déficit ya incalculable y ahora para hacer frente a la crisis han votado no se sabe cuántos trillones de dólares que provienen de falsificación de moneda, porque están impidiendo dólares sin cuartel y esa práctica tiene que tener necesariamente un pavoroso cuadro futuro inflacionario. A qué se debe el déficit incalculable? Pues principalmente a los desembolsos de las guerras que acometen como por ejemplo en Afganistán y en Iraq. ¿Podrá Obama manejar esta situación? Dios así lo quiera. "In God we trust”

Se encuentra un país con once millones de desocupados, un país que se basa en la competencia despiadada y no en la solidaridad, consumista, el principal destino del narcotráfico, el mayor productor de armas, el principal responsable del desequilibrio ambiental y el campeón de la pornografía.

No le resultará fácil mantener la hegemonía cuando las Naciones Unidas no son democráticas a la vez que surgen nuevos polos de países-potencia como la China, la India y el Brasil.

La divisa norteamericana que es el dólar sirve todavía como referencia universal para establecer el valor económico de todo cuanto existe, comodities, y monedas internacionales tales como el euro, la esterlina y el yen, y el mismo sol peruano incluso. Pero esta moneda que es el dólar y que sirve para medir todo no tiene ella misma una referencia ya que su valor se basa en la nada pura y simple y aún se mantiene la premisa dogmática, puramente fiduciaria, de que los bonos del tesoro americano son los únicos papeles en el universo entero que tienen riesgo cero. Sin embargo no es lo más probable que esa presunción de pura confianza se mantenga perpetuamente, primero de todo porque nada dura perpetuamente y segundo porque es difícil de creer que dada la situación actual en Estados Unidos haya algo que tiene riesgo cero.

Una decisión importante que se ha tomado en el grupo G 20 en Londres corroborada por todos los países más importantes del planeta se refiere al refuerzo del Fondo Monetario Internacional adjudicándole la responsabilidad de manejar los miles de millones de dólares destinados a sanear las economías 
monetarias y las instituciones financieras en descrédito. Pero el presidente Obama sabe muy bien (y también Joseph Stiglitz premio Nobel estadounidense) que el Fondo Monetario está en decadencia desde hace muchos años por incompatible con la eficiencia en los países en los cuales metió la mano con recetas muchas veces duplicadas y con el soterrado interés mezquino y exclusivo de que pagaran la deuda externa. ¿Qué pasaría si el Fondo Monetario Internacional investiga y analiza las políticas financiera y monetaria de Estados Unidos? ¿Acaso aprobaría el examen? Y cuál receta le aplicaría?

¿Quién decide cuál país puede tener fuerza nuclear, misiles de largo alcance y cuál no puede? Según el criterio de los Estados Unidos Israel sí puede pero Irán, por ejemplo, no puede. ¿Por qué? El presidente Obama será capaz de contestar satisfactoriamente? Hay que bloquear a Cuba porque en Cuba no se practica la democracia. En el Vaticano tampoco se practica la democracia y menos aún en las Naciones Unidas. El problema principal en este terreno es que es muy difícil evaluar la objetividad o la arbitrariedad pero en todos los casos el tema central radica en el hecho de que no se acepta que nadie se arrogue el privilegio exclusivo de decidir.

El tema principal de la agenda pendiente es el de la polarización de fuerzas, equilibrio que se suspendió al concluirse la Guerra Fría con la consiguiente fragmentación de la Unión Soviética y que posteriormente se agravó con la tragedia de las torres gemelas. Asoman fuerzas embrionarias que confunden el panorama universal, y no existe la necesaria bipolaridad que es un decreto de la manifestación en todas sus formas. Todo lo que está regido bajo el cielo está subordinado a la bipolaridad, se trata de una ley inexorable y evidente. El planeta tiene dos polos, mientras en el hemisferio sur es de noche en el hemisferio norte es de día, cuando aquí es invierno allá es verano. Está el blanco y el negro, lo masculino y lo femenino, lo alto y lo bajo. Así también podemos decir que si no existiera el dolor no existiría el placer, o viceversa. Son innumerables los ejemplos que se pueden ofrecer sobre este particular y el gráfico más explícito es el del Yin/Yan símbolo de la complementariedad de los opuestos.

Si se observa con detenimiento la realidad se puede comprobar que nada escapa a la necesaria "coincidentia opossitorum" porque incluso el bien y el mal dependen uno de otro en el sentido que si no existiera uno no tendría razón de ser el otro. Desde el punto de vista político lo más saludable y aconsejable es la bipolaridad puesto que una proliferación innumerable de partidos e ideologías conducirían inevitablemente al caos.

En tiempos recientes, sin embargo, se postuló la teoría de que como consecuencia del fracaso del abanderado del régimen socialista que era la Unión Soviética el escenario mundial estaría signado por la monopolaridad o sea un centro único de comando, pero la crisis financiera internacional indujo a los analistas a sugerir que eso tampoco era así, sino que estábamos experimentando la "apolaridad" donde ningún punto de referencia sería válido o prevaleciente. Pues bien, ni la multipolaridad como tampoco la apolaridad son capaces de subsistir en la existencia. Nuestro planeta describe una elipse en su trayectoria alrededor del sol y la geometría analítica enseña que la elipse tiene dos nodos, dos centros. Valga este comentario como un ejemplo adicional que refuerza lo antedicho.

Recapitulando nuestra cuestión central que es el presidente Obama y el cambio, anotemos que lo que se propone el nuevo presidente americano es restituir el sitial predominante de Estados Unidos en el planeta y evidentemente hay que reconocer que 
ese es su desafío, pero varias interrogantes surgen al analizar su propósito. Suponiendo que lo lograra, la primera prueba consistiría en su duración, pero paralelamente está pendiente el tema de la contrapartida, del contrapeso necesario. Todo parece indicar que el aglutinamiento histórico de la otra cara de la medalla corresponde a China cuya pujanza viene estando demostrada durante más de una década consecutiva con resultados antes insospechados cuanto ahora sorprendentes. Es inédito el desenvolvimiento reciente de la China porque al tiempo que suscribe en la economía un diseño de economía social de mercado (o cuando menos tiende a eso), en la política mantiene un férreo sistema vertical con un buró, organismo colegiado de dirección, poderoso, enorme, participativo, pero de absoluta concentración del poder.

Lo que es indiscutible es que hasta ahora no se ha encontrado un sistema perfecto y muy probablemente nunca se encontrará porque por naturaleza la humanidad es defectuosa y en muchas ocasiones, tal vez la mayoría, la humanidad es contradictoria.

Para concluir, el gran cambio que acomete Obama, en el fondo, debe apuntar a transformar el alma (the soul, Mr. President) de su pueblo que, perdida la inocencia con la tragedia de las torres gemelas debe ser capaz de comprender con sagacidad y humildad que han cometido muchos errores que es menester rectificar. Nunca, excepción hecha del ataque a Pearl Harbor en diciembre de 1941, en Hawai, cuna de Obama, pero en un espacio aislado que no tuvo impacto mayor como en cambio sí lo fue en el corazón de Nueva York. Debe comprender que Estados Unidos ha perdido prestigio y se ha equivocado en sus maniobras y en sus contradicciones, que ha decepcionado entre lo que proclama teóricamente y lo que ejecuta en la práctica.
Tiene el presidente Obama una enorme ventaja que lo asiste y dicha ventaja radica en la obra de su predecesor que de acuerdo con la inmensa mayoría de los observadores ha sido el hombre más oscuro que haya registrado la historia reciente. Cuando un presidente joven, inteligente y honesto, como Obama, asume el cargo sucediendo a alguien cuyas marcas están por debajo de lo deficiente, tiene, por lo menos al comienzo, todas las posibilidades de brillar.

\section{UNA REFLEXIÓN FINAL}

A pesar de que el cambio está ansiosamente presente en todas las voluntades y los corazones es obligatorio preguntarse si siempre el cambio es aconsejable porque con la cultura y tecnología impulsada por la velocidad uniformemente acelerada, pareciera que se impone el cambio permanente de donde se desprendería que el cambio es bueno per sé, que es aconsejable intrínsecamente lo que hace suponer por lógica que todo lo anterior está mal y ese juicio de valor no solamente es falso y temerario sino que conduce inevitablemente a la precariedad y a la insubsistencia de todas las instituciones, valores y bienes. Por ejemplo, si alguien está sano el cambio no le conviene y si vive en condiciones de paz está claro que tampoco le conviene cambiar.

Se dice que algunos ciudadanos son retrógrados porque le tienen miedo al cambio $y$ esto puede resultar cierto, pero igualmente es necesario reflexionar sobre las ventajas de la estabilidad puesto que lo contrario es la crisis y la experiencia de la crisis es un tránsito que puede llevar a mejorar pero también a empeorar. De otro lado, vivir en crisis constante es una tortura que por desgracia es el signo actual que caracteriza 
a nuestra sociedad y su manifestación visible es el estrés que se puede traducir como angustia. La precariedad consiste en la inestabilidad de todas las esferas en las que vivimos, la familia, el trabajo, la economía y la política y tiene que ser evaluada advirtiendo que ese desequilibrio, esa inestabilidad se califica como un mal y no como un bien $y$ en resumidas cuentas se debe reconocer que el origen de la precariedad obedece directa o indirectamente al impulso del cambio constante.

Es verdad, sin embargo, que existen circunstancias claras donde el cambio se impone como es la situación actual en los Estados Unidos donde resultaría absurdo reafirmar la enorme presencia de tendencias perversas y equivocadas. Evidentemente tiene razón el presidente Obama cuando enarbola la bandera del cambio y eso lo ha comprendido y respaldado mayoritariamente su pueblo.

\section{CONCLUSIONES}

Barack Hussein Obama Dunham, ex senador por Illinois y flamante presidente de los Estados Unidos, ha accedido a la más alta magistratura focalizando como mensaje central la necesidad de cambio.

Eso significa que la nación norteamericana, pese a ser la más poderosa del mundo, se encuentra profundamente insatisfecha.

Un análisis histórico permite comprobar que los Estados Unidos de Norteamérica se encuentran en abierta decadencia desde la década de 1960 cuando acometieron la fallida y absurda guerra del Vietnam.

Luego de periódicas recuperaciones han profundizado sus errores siendo los más graves y recientes la agresión contra Iraq en materia política y el desencadenamiento de la crisis internacional en materia financiera.

El presidente Obama está siendo percibido como una figura providencial y tal vez como una última oportunidad de recuperación para el pueblo americano.

\section{REFERENCIAS BIBLIOGRÁFICAS}

1. Soros, G. (1998). La crisis del capitalismo global. 1.a edición. Argentina: Editorial Sudamericana.

2. Spengler, O. (1935). La decadencia de Occidente. Chile: Editorial Osiris (Biblioteca de Autores Célebres).

3. Stiglitz J. (2007). El malestar en la globalización. 1. ${ }^{a}$ edición. Madrid: Editorial Punto de Lectura.

4. StiglitzJ. (2008). La guerra de los tres billones: El verdadero coste del conflicto en Iraq. 1. ${ }^{a}$ edición, Madrid: Editorial Taurus.

5. Toynbee A. (1975). Estudio de la Historia. España: Alianza Editorial. 